Pathologe 2015 · 36:571

DOI 10.1007/s00292-015-0035-x

Online publiziert: 27. Mai 2015

(c) Springer-Verlag Berlin Heidelberg 2015

S. Ting · S.T. Schmid · S. Synoracki $\cdot$ K.W. Schmid

Institut für Pathologie, Universitätsklinikum Essen, Universität Duisburg-Essen, Essen, Deutschland

\title{
Erratum zu: Die C-Zellen der Schilddrüse und ihre Pathologie
}

\section{Teil 1: Normale C-Zellen - Hyperplasie der C-Zellen - Präkanzerose des familiären medullären Karzinoms}

\section{Erratum zu:}

Pathologe (2015)

DOI 10.1007/s00292-015-0019-x

Aufgrund eines technischen Fehlers wurde bei diesem Beitrag S.T. Schmid in der Autorenschaft leider nicht aufgeführt.

Wir bitten, die korrekten Angaben zu beachten und den Fehler zu entschuldigen.

Die Redaktion

\section{Korrespondenzadresse}

\section{Univ.-Prof. Dr. K.W. Schmid} Institut für Pathologie

Universitätsklinikum Essen

Universität Duisburg-Essen

Hufelandstraße 55, 45147 Essen

kw.schmid@uk-essen.de 